J. Dairy Sci. 92:589-598

doi:10.3168/jds.2008-1551

(c) American Dairy Science Association, 2009.

\title{
Evaluation of antioxidant and proinflammatory gene expression in bovine mammary tissue during the periparturient period
}

\author{
S. L. Aitken, ${ }^{\star}$ E. L. Karcher, ${ }^{\star}$ P. Rezamand, ${ }^{\star}$ J. C. Gandy, ${ }^{\star}$ M. J. VandeHaar,† A. V. Capuco,‡ \\ and L. M. Sordillo*1 \\ ${ }^{*}$ Department of Large Animal Clinical Sciences, and \\ †Department of Animal Science, Michigan State University, East Lansing 48824 \\ łBovine Functional Genomics Laboratory, USDA, ARS, Beltsville, MD 20705
}

\begin{abstract}
The incidence and severity of mastitis can be high during the period of transition from pregnancy to lactation when dairy cattle are susceptible to oxidative stress. Oxidative stress may contribute to the pathogenesis of mastitis by modifying the expression of proinflammatory genes. The overall goal of this study was to determine the relationship between critical antioxidant defense mechanisms and proinflammatory markers in normal bovine mammary tissue during the periparturient period. Mammary tissue samples were obtained from 12 cows at 35, 20, and $7 \mathrm{~d}$ before expected calving and during early lactation (EL, 15 to $28 \mathrm{~d}$ in milk). Enzyme activities for cytosolic glutathione peroxidase and phospholipid hydroperoxide glutathione peroxidase were relatively low during the dry period, but increased during EL, whereas activity of thioredoxin reductase 1 did not change significantly as a function of time. In contrast, gene expression for these antioxidant selenoproteins and for heme oxygenase- 1 gradually decreased as parturition approached and then increased during EL. The expression of intercellular vascular adhesion molecule-1 and vascular cell adhesion molecule-1 followed a similar trend where mRNA abundance gradually declined as parturition approached with a slight rebound in EL. Gene expression of the pro-oxidant, 15-lipoxygenase 1, which is known to increase during times of oxidative stress, also increased dramatically in mammary tissue from EL cows. Expression of the proinflammatory cytokines, IL- $1 \beta$, IL-6, and IL- 8 did not change significantly during the periparturient period. Strong positive correlations were found between several antioxidant enzymes (cytosolic glutathione peroxidase, thioredoxin reductase 1 , and heme oxygenase-1) and vascular adhesion molecules (intercellular vascular adhesion molecule-1, vascular cell adhesion
\end{abstract}

Received July 14, 2008.

Accepted September 22, 2008.

${ }^{1}$ Corresponding author: Sordillo@msu.edu molecule-1) suggesting a protective response of these antioxidants to an enhanced proinflammatory state. Ability to control oxidative stress through manipulation of key antioxidant enzymes in the future may modify the proinflammatory state of periparturient cows and reduce incidence and severity of some diseases such as mastitis.

Key words: mammary gland, periparturient period, oxidative stress, inflammation

\section{INTRODUCTION}

Dairy cattle experience increased incidence of disease, such as mastitis, during the periparturient period when host defense mechanisms are compromised. Several physiological changes occur in periparturient dairy cows that may contribute to altered immune and inflammatory responses including overall nutritional status, energy metabolism, and changes in hormone profiles (Sordillo, 2005). Another factor contributing to compromised immunity and increased incidence of disease may be the progressive development of oxidative stress (Miller et al., 1993; Sordillo, 2005; Sordillo and Aitken, 2009). Oxidative stress occurs when there is an imbalance between production of reactive oxygen species (ROS) and reduced host antioxidant capabilities (Valko et al., 2007). During the periparturient period, dairy cows experience extreme shifts in cellular metabolism as the mammary gland prepares for the ensuing lactation (Sordillo and Aitken, 2009). The onset of copious milk synthesis and secretion requires large amounts of molecular oxygen for aerobic metabolism. Free radicals are formed as a normal end product of cellular metabolism arising from either the mitochondrial electron transport chain or from stimulation of $\mathrm{NADPH}_{2}$ (Valko et al., 2007). Therefore, the considerable increase in oxygen requirements during heightened metabolic demands results in augmented rates of ROS production. Indeed, several recent studies showed that production of excess ROS in the peripheral blood of dairy cattle during the periparturient period can overwhelm certain 
antioxidant defenses, resulting in increased oxidative stress (Bernabucci et al., 2005; Castillo et al., 2005; Sordillo et al., 2007).

Dairy cattle have several known endogenous antioxidant defense mechanisms that can counteract the harmful effects of ROS accumulation, but it is the selenium-dependent selenoproteins that have been studied extensively with respect to mammary gland health (Sordillo and Aitken, 2009). Selenium supplementation reduces the incidence and severity of mastitis (Smith et al., 1984). The beneficial effects of selenium supplementation are thought to be due to the actions of certain antioxidant selenium-dependent enzymes, which have a selenocysteine residue incorporated into their active site. These selenoenzymes function in part by reducing harmful ROS and other fatty acid hydroperoxides to less-reactive waters and alcohols, respectively. Approximately 25 selenoproteins have been identified in humans (Papp et al., 2007), but the selenoprotein most often associated with antioxidant functions in cattle is cytosolic glutathione peroxidase (GPX1; Smith et al., 1997). Indeed, GPX1 activity is often used as a diagnostic tool when assessing the selenium status of dairy cows or as an indicator of increased ROS accumulation. Several recent studies, however, now document the presence of other selenoprotein enzymes in the blood and tissues of dairy cattle that may play an important role in controlling oxidative stress, including thioredoxin reductase 1 (TrxR1) and phospholipid hydroperoxide glutathione peroxidase (GPX4; Bruzelius et al., 2007; Sordillo et al., 2007). In addition to their ROS scavenging functions, many selenoproteins are essential for regulating cellular redox status and influencing the expression of redox-regulated genes. For example, TrxR1 regulates expression of other important antioxidant defenses such as heme oxygenase 1 (HO-1), which is upregulated in response to ROS and converts the pro-oxidant heme into bilirubin, carbon monoxide, and iron (Balla et al., 2007). Although HO-1 has not been studied in dairy cattle in vivo, HO-1 is upregulated in cultured bovine aortic endothelial cells under oxidative stress conditions following reduced TrxR1 activity (Trigona et al., 2006). Despite significant evidence supporting a role for antioxidants in enhancing resistance to mastitis (Sordillo and Aitken, 2009), there is no information as to how the expression of specific antioxidant defenses change in mammary tissues during the periparturient period when dairy cattle experience increased oxidative stress.

There are several human inflammatory-based diseases that occur as a consequence of oxidative stress, including cardiovascular disorders, diabetes, and cancer (Valko et al., 2007; Bonomini et al., 2008). The pathologies of these diseases may result from the enhanced expression of redox regulated proinflammatory factors such as eicosanoids and cytokines. For example, the metabolism of arachidonic acid through the 15-lipoxygenase 1 (15-LOX1) pathway causes the formation of 15-hydroperoxyeicosatetraenoic acid (15-HPETE), which is enhanced during oxidative stress (Cao et al., 2000). Increased 15-HPETE concentration in tissue and cells is associated with enhanced expression of certain proinflammatory genes such as intercellular adhesion molecule-1 (ICAM-1) and vascular cell adhesion molecule-1 (VCAM-1) (Bonomini et al., 2008). Vascular adhesion molecules are essential for transendothelial leukocyte migration to the site of infection. Enhanced expression of either ICAM-1 or VCAM-1, however, can lead to pathologic proinflammatory conditions (Radi et al., 2001; Sordillo et al., 2008). Relative to dairy cattle health, oxidative stress enhanced 15-LOX1 activity and accumulation of 15-HPETE in bovine endothelial cells and caused a significant increase in ICAM-1 expression (Sordillo et al., 2008). The expression of VCAM-1 protein in bovine mammary tissues also was reported to increase significantly during colostrogenesis when dairy cattle are known to experience oxidative stress (Hodgkinson et al., 2007).

Oxidative stress increases the expression of acute phase cytokines that also can exacerbate tissue damage during severe inflammatory responses (Cuschieri and Maier, 2007). Proinflammatory cytokines are thought to play an important role in the mammary gland's response to a variety of mastitis-causing organisms including Staphylococcus aureus, Streptococcus uberis, and Escherichia coli (Oviedo-Boyso et al., 2007). Indeed, numerous studies showed that tumor necrosis factor- $\alpha$ (TNF- $\alpha$ ), IL-1 $\beta$, IL-6, and IL-8 were linked with the severity of coliform mastitis during the periparturient period when dairy cattle experience oxidative stress (Oviedo-Boyso et al., 2007). Expression of TNF- $\alpha$ from isolated mononuclear cells in either peripheral blood or supramammary lymph nodes was greater in the periparturient period compared with mid to late lactation (Sordillo et al., 1995). An inverse relationship between TrxR1 activity and TNF- $\alpha$ production by peripheral blood mononuclear cells obtained from cows experiencing oxidative stress also was recently reported (O'Boyle et al., 2006).

Collectively, these previous data support the contention that reduced antioxidant capacity and enhanced proinflammatory status may be related and that this relationship may play a role in dairy cattle disease susceptibility during the periparturient period. However, there is no information linking the antioxidant and inflammatory status in normal bovine mammary tissue during the periparturient period when dairy cattle are susceptible to increased incidence of disease. Such 
information may be useful in finding ways to decrease the incidence or severity of periparturient cow diseases. The goal of this study was to determine the relationship between expression of critical antioxidant defense mechanisms and proinflammatory markers in normal mammary tissue during the periparturient period when dairy cattle experience oxidative stress.

\section{MATERIALS AND METHODS}

\section{Animals}

Use of animals for these investigations was approved by the Beltsville Agricultural Research Center's Animal Care and Use Committee. Mammary tissue samples were obtained from Holstein dairy cows in the dry period (35 to $7 \mathrm{~d}$ before expected parturition date) and early lactation (EL). Multiparous (second or greater lactation) cows were dried off $60 \mathrm{~d}$ before expected calving date at which time average milk yield (mean \pm SEM) was 10.2 $\pm 3.00 \mathrm{~kg} / \mathrm{d}$ (data not shown). One week before initiation of the study, SCC and bacteriological analyses were performed on foremilk samples aseptically collected. All cows were free of mastitis. Dry cows were killed at the USDA abattoir (Beltsville, MD) at $-35 \mathrm{~d}(\mathrm{n}=3),-20$ $\mathrm{d}(\mathrm{n}=3)$, and $-7 \mathrm{~d}(\mathrm{n}=3)$ before expected calving date and mammary tissue samples were obtained after removing extra-parenchymal tissues and processed as described previously (Capuco et al., 1997). Mammary tissue samples were also obtained from lactating cows that were between 15 and 28 DIM (EL; $\mathrm{n}=3$ ); these samples were parenchymal biopsies as described previously (Sharma et al., 1994). All tissue samples were immediately frozen and stored at $-70^{\circ} \mathrm{C}$.

\section{Quantitative Real-Time PCR}

Total RNA was isolated from mammary tissue using the RNeasy Lipid Tissue Mini Kit from Qiagen (Valencia, CA). The RNA was DNase digested using the RNase-Free DNase Set (Qiagen) and cDNA was then synthesized using the High Capacity cDNA reverse transcriptase kit with RNA inhibitor (Applied Biosystems, Foster City, CA). All of the primers used in the present study were derived from the Bos taurus genome (GenBank) and are shown in Table 1. Realtime quantitative PCR (qPCR) was carried out in a 7500 Fast Real-Time PCR system (Applied Biosystems) using custom-designed TaqMan minor groove binding probes from Applied Biosystems. The PCR was performed in triplicate using a $20-\mu \mathrm{L}$ reaction mixture per well, containing $10 \mu \mathrm{L}$ of TaqMan Fast Universal PCR Master Mix (2×, Applied Biosystems), $1 \mu \mathrm{L}$ of $(20 \times)$ Custom TaqMan Gene Expression Assay
Mix (Applied Biosystems), $100 \mathrm{ng}$ of cDNA, and the balance was nuclease-free water. Targeted genes were amplified with the reaction mixture described above. A $(20 \times)$ Custom Taqman Gene Expression Assay Mix for bovine ribosomal protein 9 (RPS9) was generated by Applied Biosystems as an endogenous control (Bionaz and Loor, 2007). The thermal cycling conditions for fast 2-step PCR were used: stage 1 enzyme activation, $95^{\circ} \mathrm{C}$ for $20 \mathrm{~s}$; stage $2,95^{\circ} \mathrm{C}$ for $3 \mathrm{~s}$; stage $3,60^{\circ} \mathrm{C}$ for 30 $\mathrm{s}$; with 40 replications through stages 2 and 3. Quantification was carried out with the relative quantification method (Livak and Schmittgen, 2001). The abundance of target genes, normalized to RPS9 (as the internal control) and relative to a calibrator, are illustrated by $2^{-\Delta \Delta C t}$, where $C_{t}$ is the cycle number at which the fluorescence signal of the product crosses an arbitrary threshold set with exponential phase of the PCR and $\Delta \Delta \mathrm{Ct}=\left(\mathrm{Ct}_{\text {target gene unknown sample }}-\mathrm{Ct}_{\mathrm{RPS} 9}\right.$ unknown sample $)-$ $\left(\mathrm{Ct}_{\text {target gene calibrator sample }}-\mathrm{Ct}_{\mathrm{RPS} 9}\right.$ calibrator sample $)$. Averaged abundance of target genes at $35 \mathrm{~d}$ before expected calving date was considered as the calibrator.

\section{GPX1 and GPX4 Activities}

Mammary tissue samples $(-35 \mathrm{~d}, \mathrm{n}=3 ;-20 \mathrm{~d}, \mathrm{n}$ $=3 ;-7 \mathrm{~d}, \mathrm{n}=3$; and $\mathrm{EL}, \mathrm{n}=3$ ) were examined for both GPX1 and GPX4 activities. Mammary tissue samples were weighed, suspended in a collecting buffer (pH 7.4) containing $263 \mathrm{~m} M$ sucrose, $21 \mathrm{mM}$ Trizma hydrochloride, and 0.1\% Triton X-100 (Sigma, St. Louis, MO), and homogenized on ice for 1 min using a Polytron homogenizer (Kinematica Inc., Bohemia, NY). Samples were then centrifuged at $13,000 \times g$ for 20 min at $4^{\circ} \mathrm{C}$, after which supernatants were collected. The activities of GPX1 and GPX4 in supernatants obtained from mammary tissue samples were determined as described previously (Sordillo et al., 1998). In the coupled enzymatic assays, while oxidation of $\mathrm{NADPH}_{2}$ was spectrophotometrically monitored, enzyme activities were determined using either hydrogen peroxide or phosphatidylcholine hydroperoxide as the substrates (for GPX1 and GPX4 activities, respectively). One unit of enzyme activity was defined as the amount of enzyme oxidizing 1 micromole of $\mathrm{NADPH}_{2}$ per minute. Data were normalized per milligram of total protein content of tissue supernatants.

\section{TrxR1 Activity}

Mammary tissue samples ( $\mathrm{n}=3$ per time point) were weighed, suspended in a collecting buffer $(\mathrm{pH}$ 7.25) containing $1 \times$ PBS with $0.02 \mu M$ EDTA (Sigma), and homogenized on ice for 1 min using a Polytron homogenizer. Samples were then centrifuged at 13,000 
$\times g$ for $20 \mathrm{~min}$ at $4^{\circ} \mathrm{C}$, after which supernatants (1 $\mathrm{mL}$ ) were concentrated using a centrifugal filter device (Millipore, Billerica, MA) with membrane nominal molecular weight limit of $30,000 \mathrm{Da}$ at $3,273 \times g$ at $4^{\circ} \mathrm{C}$ for approximately 10 min reaching a final volume of 500 $\mu \mathrm{L}$. Enzyme activity was determined using the standard insulin-based method previously developed (Holmgren and Björnstedt, 1995). Each well of a 96-well plate contained $33 \mu \mathrm{L}$ of a reaction mixture consisting of $0.08 \mathrm{M}$ HEPES, $3.03 \mathrm{~m} M$ EDTA, $0.6048 \mathrm{~m} M$ of insulin, and $0.61 \mathrm{mM}$ of $\mathrm{NADPH}_{2}$. Samples were run in the presence and absence of $16 \mu M E$. coli thioredoxin (Sigma). The reaction was started by addition of $9 \mu \mathrm{L}$ of tissue supernatants. Following a 60 -min incubation at $37^{\circ} \mathrm{C}$, the reaction was stopped by addition of $150 \mu \mathrm{L}$ of stopping buffer consisting of $1.0 \mathrm{mM}$ 5,5-dithio-bis(2-nitrobenzoic acid) (DTNB) $/ 6 M$ guanidine hydrochloride in 0.2 $M$ Tris-HCl, $\mathrm{pH}$ 8.0. The absorbance was read at 415 $\mathrm{nm}$. The reaction without thioredoxin was subtracted from the thioredoxin-dependent reaction and TrxR1 activity was expressed as $\mathrm{A}_{415}$ units $\times 1,000 /(\min \times$ mg protein) (Hill et al., 1997).

\section{Statistical Analyses}

All statistical analyses were conducted using SAS, version 9.1.2 for Windows (SAS Institute Inc., Cary, $\mathrm{NC}$ ). Pearson correlation coefficients (r) were computed to determine relationships between antioxidants and proinflammatory markers and adhesion molecules. The effect of lactation stage (35, 20, $7 \mathrm{~d}$ before expected calving date and EL) on the relative abundance of mRNA and antioxidant enzyme activities of the mammary tissue was tested by the MIXED procedure of SAS. Cow was considered as a random factor. Protected least significant difference was used to compare least squares means and data are reported as least squares means \pm standard error of the means. Significant differences were declared at $P \leq 0.05$.

\section{RESULTS AND DISCUSSION}

\section{Antioxidant Defense}

The incidence and severity of mastitis can be high during the periparturient period when dairy cattle are known to experience oxidative stress (Bernabucci et al., 2005; Castillo et al., 2005; Sordillo et al., 2007). Selenium supplementation to periparturient cows reduces the incidence and severity of mastitis probably through the actions of selenoproteins (Smith et al., 1984). Cytosolic glutathione peroxidase is the predominant intracellular form of glutathione peroxidase and is the most extensively studied selenoprotein in dairy cattle

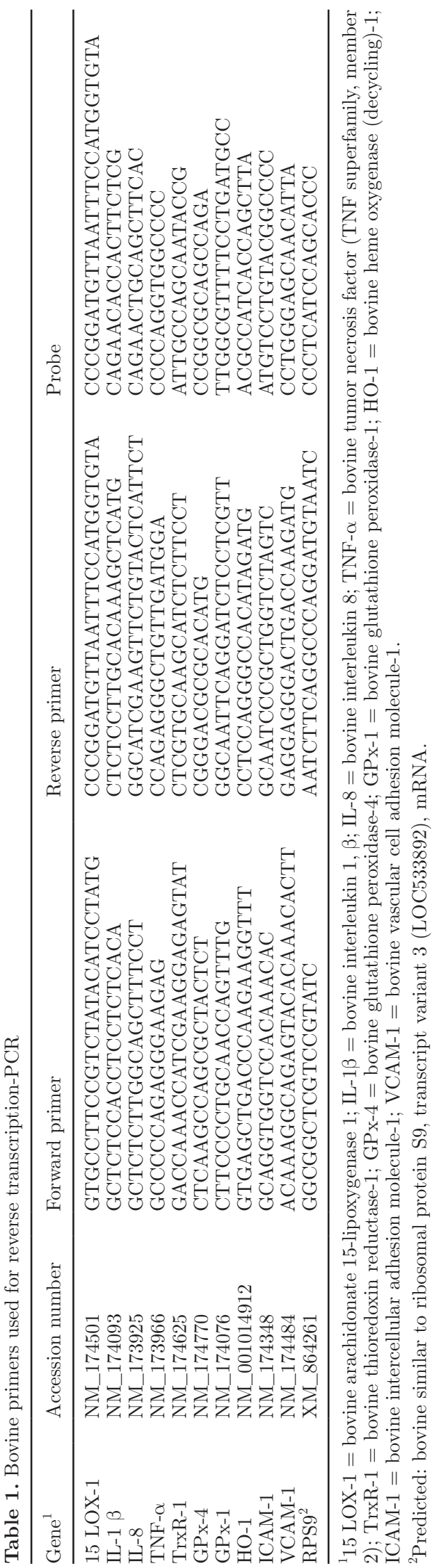


A

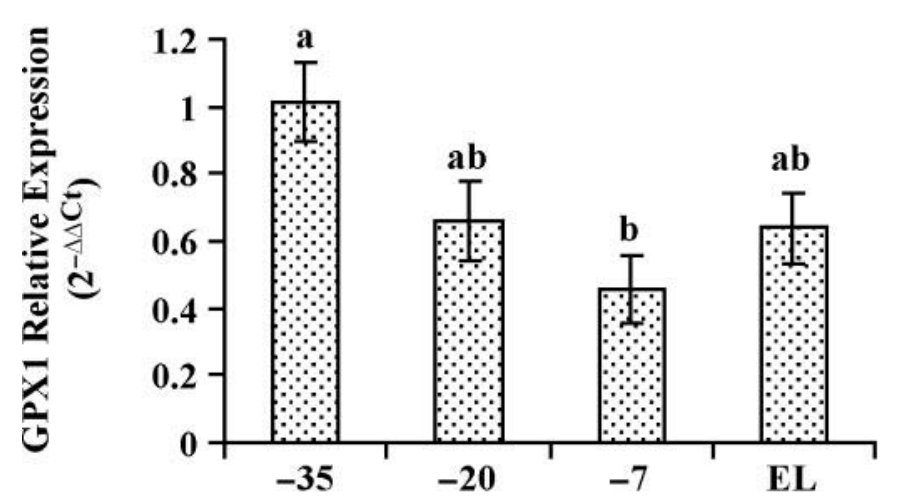

B

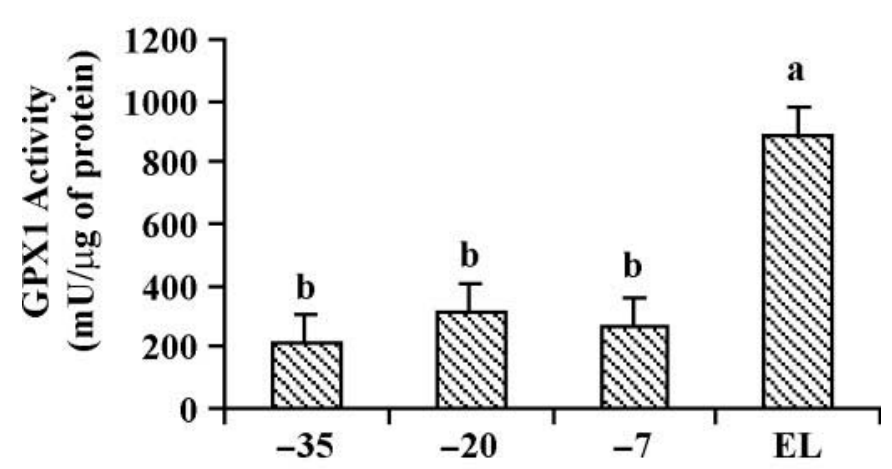

Time Relative to Calving (d)

Figure 1. Data reported as least squares means \pm SEM. Significant differences $(P<0.05)$ between days are represented by different letters. (A) Alterations in mRNA abundance of glutathione peroxidase 1 (GPX1) in the bovine mammary tissue obtained at $-35,-20$, and -7 $\mathrm{d}$ relative to calving and at early lactation (EL). Data were analyzed by the $2^{-\Delta \Delta \mathrm{Ct}}$ method with $-35 \mathrm{~d}$ as the reference expression point. (B) Enzyme activity of GPX1 in the bovine mammary tissue obtained at $-35,-20$, and $-7 \mathrm{~d}$ relative to calving and at EL.

(Smith et al., 1997). It converts ROS to less reactive metabolites and thus protects tissues against oxidative damage (Papp et al., 2007). In the current study, GPX1 mRNA abundance was highest at $35 \mathrm{~d}$ before expected calving, gradually declined as parturition approached, but rebounded slightly during EL $(P<0.03$; Figure 1A). Enzyme activity for GPX1 in mammary tissue remained relatively low during the dry period and increased during EL $(P<0.02$; Figure 1B). An increase in GPX1 activity during EL may be due to a cytoprotective response against oxidative damage that occurs during the onset of copious milk synthesis and secretion. Changes in GPX1 enzyme activity observed in this study are consistent with previous reports in plasma and whole blood where GPX activity increased at calving and during EL (Bernabucci et al., 2005; Sor- dillo et al., 2007). The disparate shifts in GPX1 mRNA and enzyme expression may be attributable to several factors. The expression of GPX1 mRNA is particularly sensitive to any changes in ROS accumulation, such that increases in GPX1 mRNA are an excellent indicator of oxidative stress. Therefore, real-time qPCR, as used in this study, may permit enhanced detection of alterations in GPX1 mRNA abundance during periods when ROS concentrations may fluctuate but overall changes in GPX1 enzymatic activity may be minor. Furthermore, enzyme activity of GPX1 can be influenced by other factors within the tissue microenvironment such as the availability and/or oxidized status of key substrates such as glutathione. Therefore, disparate trends in GPX1 mRNA expression and GPX1 enzymatic activity also may be explained by changes in the redox status of tissues at the time of sample collection.

Phospholipid hydroperoxide glutathione peroxidase (GPX4) is present in cytosolic, nuclear, and mitochondrial membranes of the cell. This enzyme has the unique ability to reduce lipid peroxides as well as soluble hydroperoxides (Papp et al., 2007). This study defines, for the first time, changes in GPX4 mRNA and enzyme activity across the periparturient period. Expression of GPX4 mRNA gradually declined as parturition approached, and increased to maximal abundance during EL $(P<0.05$; Figure 2A). The GPX4 enzyme activity, however, followed a similar pattern as GPX1 activity and was greatest in EL compared with all other time points $(P<0.01$; Figure $2 \mathrm{~B})$. Although a similar trend for GPX1 and GPX4 enzyme activities was demonstrated in the current study, the mRNA expression of GPX4 declined $37 \%$ between 35 and 7 d prepartum, whereas the mRNA expression of GPX1 declined by $56 \%$ during the same time period. In contrast to GPX1, the enzyme activity of GPX4 is more slowly depleted and tends to be conserved during periods of selenium deficiency (Bruzelius et al., 2007). Furthermore, knocking out the GPX4 gene in mice results in embryonic lethality, whereas GPX1 knockout mice develop normally (Brigelius-Flohe, 2006). Based on these data, we suggest that GPX4 plays a vital role for countering oxidative stress in the periparturient dairy cow.

Similar to GPX1, TrxR1 is present in the cytosol and is capable of the direct reduction of lipid hydroperoxides and hydrogen peroxide (Papp et al., 2007). As observed for GPX1 and GPX4, TrxR1 mRNA expression in mammary tissue declined as parturition approached and was lowest at $\mathrm{d}-7(P<0.01$; Figure $3 \mathrm{~A})$. Thus, the mRNA expression values for all 3 selenoproteins were lowest in mammary tissue at $7 \mathrm{~d}$ before expected calving. In contrast to the enzymatic activities for the other selenoproteins examined, TrxR1 activity did not change relative to time of calving (Figure 3B). Perhaps 
A

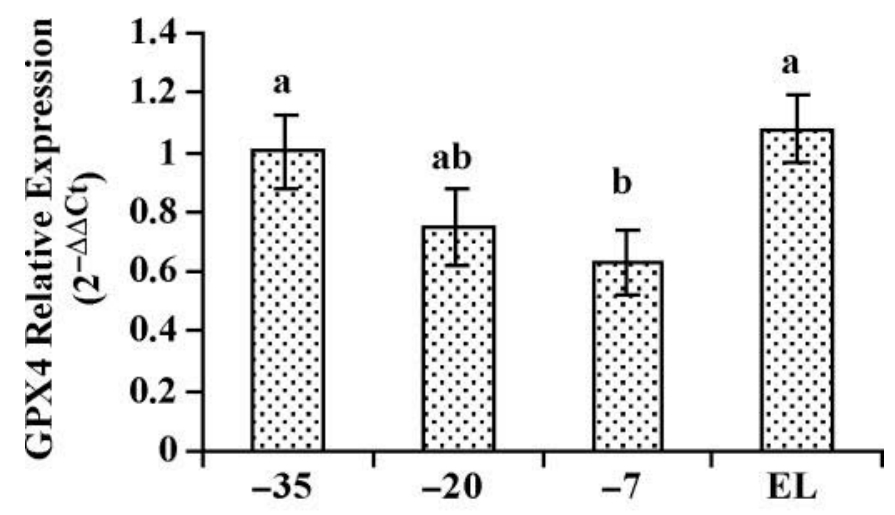

B

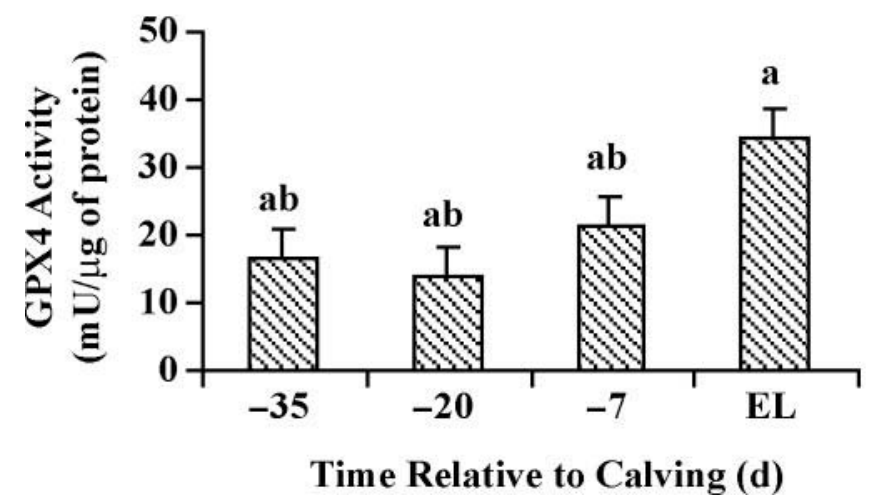

Figure 2. Data reported as least squares means \pm SEM. (A) Alterations in mRNA abundance of phospholipid hydroperoxide (GPX4) in the bovine mammary tissue obtained at $-35,-20$, and -7 $\mathrm{d}$ relative to calving and at early lactation (EL). Data were analyzed by the $2^{-\Delta \Delta \mathrm{Ct}}$ method with $-35 \mathrm{~d}$ as the reference expression point. Significant differences $(P<0.05)$ between days are represented by different letters. (B) Enzyme activity of phospholipid hydroperoxide (GPX4) in the bovine mammary tissue obtained at $-35,-20$, and -7 $\mathrm{d}$ relative to calving and at early lactation (EL).

this is partly because the TrxR 1 enzymatic activity in mammary tissues was extremely low regardless of lactation stage. Indeed, the relative mammary tissue TrxR1 activity was lower when compared with even the lowest standard that was within the reliable detection limits of the enzymatic assay used in this study. Sordillo et al. (2007) demonstrated TrxR1 activity to be decreased in peripheral blood mononuclear cells (PBMC) isolated from dairy cows at $3 \mathrm{wk}$ postpartum compared with prepartum values: however, this systemic decrease may not reflect changes occurring locally within mammary tissue. Results from Bruzelius et al. (2007) suggest that TrxR1, although not as sensitive as GPX1, is sensitive to changes in selenium status as TrxR1 activity was positively correlated to selenium concentrations in their study. However, TrxR mRNA expression and enzyme
$\mathbf{A}$
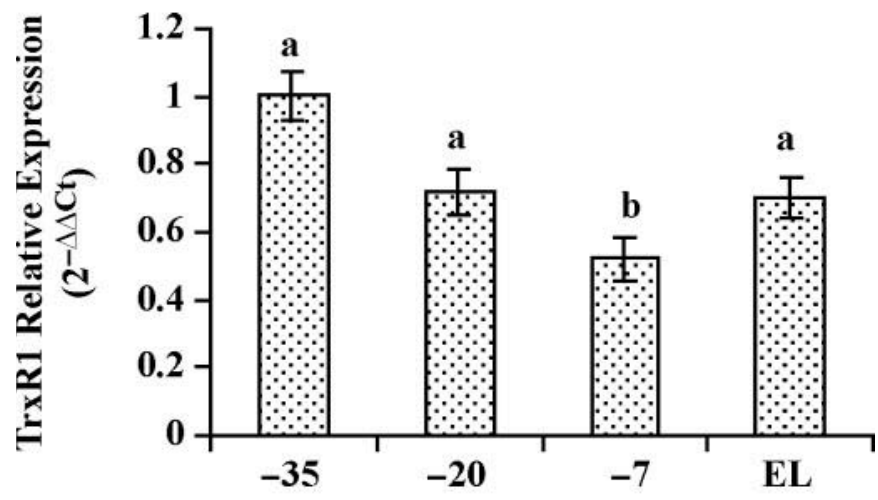

Time Relative to Calving (d)

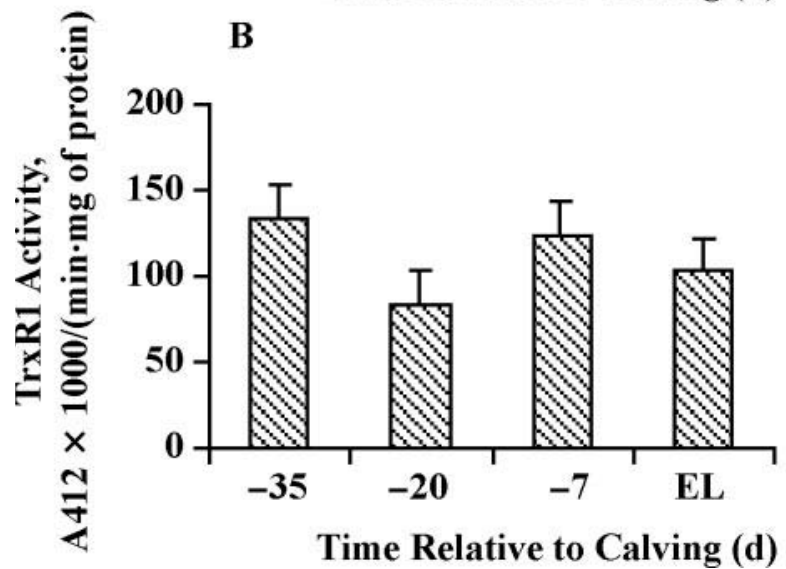

Figure 3. Data reported as least squares means \pm SEM. (A) Alterations in mRNA abundance of thioredoxin reductase (TrxR1) in the bovine mammary tissue obtained at $-35,-20$, and $-7 \mathrm{~d}$ relative to calving and at early lactation (EL). Data were analyzed by the 2 $-\Delta \Delta \mathrm{Ct}$ method with $-35 \mathrm{~d}$ as the reference expression point. Significant differences $(P<0.05)$ between days are represented by different letters. (B) Enzyme activity of TrxR1 in the bovine mammary tissue obtained at $-35,-20$, and -7 d relative to calving and at EL. The enzyme activity is expressed as $\mathrm{A}_{412}$ units $\times 1000 /(\min \times \mathrm{mg}$ protein $)$.

activity in rat aortas have demonstrated that other regulatory factors may be more important for TrxR activity other than selenium status such as relative ROS accumulation (Wu et al., 2003).

Although the antioxidant potential of various selenoproteins were defined, we also were interested in evaluating the expression of the non-selenium-dependent antioxidant, HO-1, because of its importance in counteracting oxidative stress in human disease. Heme oxygenase 1 is the rate-limiting enzyme in heme degradation and is responsible for catalyzing the reaction that produces biliverdin, ferritin, and carbon monoxide from free heme (Balla et al., 2007). This is important because free heme is cytotoxic to cells and promotes inflammation. Biliverdin and ferritin are both substances with antioxidant properties. This is the first study to 

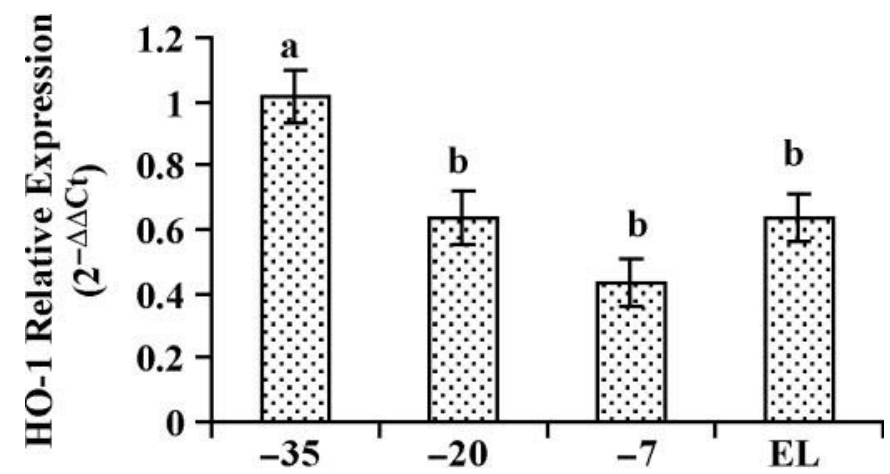

Time Relative to Calving (d)

Figure 4. Alterations in mRNA abundance of heme oxygenase-1 (HO-1) in the bovine mammary tissue obtained at $-35,-20$, and $-7 \mathrm{~d}$ relative to calving and at early lactation (EL). Data were analyzed by the $2^{-\Delta \Delta \mathrm{Ct}}$ method with $-35 \mathrm{~d}$ as the reference expression point. Data reported as least squares means \pm SEM. Significant differences $(P<$ $0.05)$ between days are represented by different letters.

report the expression of HO-1 transcripts in mammary tissue of periparturient dairy cows; however, HO-1 has been shown to be regulated by selenoproteins in bovine endothelial cell cultures (Trigona et al., 2006) and can also participate in the inflammatory process (Wagener et al., 1999). Expression of HO-1 was highest at d -35 relative to all other time points $(P<0.01)$ (Figure 4$)$. Unlike our findings for GPX4 and TrxR1, the rebound in HO-1 mRNA in EL tissues was not statistically significant. The lack of an increase in HO-1 expression at parturition may indicate an inadequate response of additional protective antioxidants such as bilirubin. Although not measured in this study, bilirubin levels decline at calving and continue to decline during the first month of lactation (Bionaz et al., 2007). The results of HO-1 mRNA expression are supportive of previous reports demonstrating the inability of periparturient dairy cows to adequately respond to oxidative stress (Bernabucci et al., 2005; Castillo et al., 2005; Sordillo et al., 2007).

\section{Proinflammatory Gene Expression}

Several previous studies have documented changes in proinflammatory cytokine expression around the time of calving in infected mammary glands. For example, increased expression of proinflammatory cytokines, including IL-1 $\beta$, IL-6, IL-8, and TNF- $\alpha$ have been linked to the pathology of acute mastitis during the periparturient period (Oviedo-Boyso et al., 2007). Macrophages are the main immune cell type present in milk and tissues of healthy, lactating mammary glands and can facilitate neutrophil recruitment via release of various cytokines such as interleukins and TNF- $\alpha$, at the initiation of inflammation. In the current study, gene expression was detected for IL-1 $\beta$, IL-6, and IL8 , but mRNA abundance did not change significantly during the periparturient period (Table 2). The trends for IL-6 and IL- 8 mRNA abundance were to decline through involution and increase slightly during EL. A declining trend in gene expression of TNF- $\alpha$, however, was detected from 20 to $7 \mathrm{~d}$ before expected parturition and mRNA abundance remained low through EL $(P$ $<0.05$ ). Sordillo et al. (1995) found that mononuclear cells isolated from peripheral blood and supramammary lymph nodes from periparturient dairy cows produced a greater amount of TNF- $\alpha$ than did mid to late lactating dairy cows following LPS stimulation. If changes in mammary expression of $\mathrm{TNF}-\alpha$ are primarily due to the presence of macrophages in the tissue, the differential expression of this cytokine may arise from differences in inherent production from monocytes in the circulation versus those in the mammary gland, as well as activation of these cells following stimulation. Perhaps most importantly is that TNF- $\alpha$ expression in this study was determined in mammary tissues that comprised several different cell populations with different capacities to produce TNF- $\alpha$ or any other cytokine. There is a limited amount of data evaluating interleukins during the periparturient period in the absence of infection. One study did show that concentrations of IL-6 in serum collected from the whole blood of periparturient dairy cows declined dramatically as parturition approached and remained low until the last sampling point at $8 \mathrm{wk}$ postpartum (Ishikawa et al., 2004). Plasma IL-8 concentrations remained low in periparturient cows $(-14$ $\mathrm{d}$ to $14 \mathrm{~d}$ relative to calving) compared with concentrations at calving (Kimura et al., 2002). Low cytokine mRNA expression in this study may be attributable to lack of expression in the absence of agonist within the local mammary tissue microenvironment.

Local endothelial cell activation is triggered by cytokines, including IL-1, IL-8, and TNF- $\alpha$, as well as other proinflammatory mediators (i.e., LPS) and results in enhanced expression of adhesion molecules. Adhesion molecules, including ICAM-1 and VCAM-1, are essential for the recruitment of inflammatory cells to the site of infection (Radi et al., 2001). In the current study, ICAM-1 mRNA expression was highest at d -35 , declined as parturition approached, but increased in EL $(P<0.004$; Table 2$)$. Expression of VCAM-1 followed a similar pattern of mRNA abundance $(P<0.02$; Table 2). Hodgkinson et al. (2007) demonstrated varying abundance of VCAM-1 protein expression in mammary tissue and supramammary lymph nodes from late gestation to EL. The authors proposed that VCAM-1 protein expression is not constitutive, but is activated by certain physiological events such as inflammation 
Table 2. Relative mRNA abundance of proinflammatory cytokines and adhesion molecules in bovine mammary gland tissues obtained at $-35 \mathrm{~d},-20 \mathrm{~d}$, and $-7 \mathrm{~d}$ before calving and during early lactation (EL: $2-4 \mathrm{wk}$ postpartum $)^{1}$

\begin{tabular}{lcccccc}
\hline Gene $^{2}$ & $-35 \mathrm{~d}$ & $-20 \mathrm{~d}$ & $-7 \mathrm{~d}$ & EL & SEM & $P$-value \\
\hline IL-1 $\beta$ & 1.16 & 0.62 & 0.79 & 0.57 & 0.26 & 0.45 \\
IL-6 & 1.59 & 0.17 & 0.20 & 0.99 & 0.49 & 0.55 \\
IL-8 & 1.19 & 0.22 & 0.35 & 3.66 & 1.53 & 0.49 \\
TNF- $\alpha$ & $1.02^{\mathrm{a}}$ & $0.95^{\mathrm{a}}$ & $0.52^{\mathrm{a}}$ & $0.41^{\mathrm{b}}$ & 0.12 & 0.05 \\
ICAM-1 & $1.04^{\mathrm{a}}$ & $0.66^{\mathrm{b}}$ & $0.38^{\mathrm{c}}$ & $0.62^{\mathrm{b}}$ & 0.09 & 0.004 \\
VCAM-1 & $1.00^{\mathrm{a}}$ & $0.71^{\mathrm{ab}}$ & $0.36^{\mathrm{b}}$ & $0.55^{\mathrm{b}}$ & 0.12 & 0.02 \\
\hline
\end{tabular}

${ }^{\mathrm{a}-\mathrm{c}}$ Means with different superscripts are significantly different $(P<0.05)$.

${ }^{1}$ Data were analyzed by the $2^{-\Delta \Delta \mathrm{Ct}}$ method with $-35 \mathrm{~d}$ as the reference expression point. Data reported as least squares means \pm SEM.

${ }^{2} \mathrm{TNF}-\alpha=$ tumor necrosis factor- $\alpha$; ICAM-1 = intercellular adhesion molecule-1; VCAM-1 = vascular cell adhesion molecule-1.

or colostrogenesis (Hodgkinson et al., 2007). Elevated expression of ICAM-1 and VCAM-1 mRNA at $\mathrm{d}-35$ relative to $\mathrm{d}-20$ and -7 in this study is consistent with the physiology of mammary involution. The significance of elevated vascular adhesion molecules in mammary tissues during EL is not known, but may be related to the increase in oxidative stress during this time. In humans, there is significant supporting evidence linking several inflammatory-based diseases to enhanced vascular adhesion molecule expression and oxidative stress (Valko et al., 2007; Bonomini et al., 2008). In this study, significant correlations were demonstrated between several antioxidants (GPX1, TrxR1, and HO-1) and proinflammatory factors (ICAM-1 and VCAM-1; Table 3). Increases in proinflammatory markers during a period when oxidative stress is known to occur, and their correlation with antioxidant markers, may indicate a role for oxidative stress in the pathogenesis of dairy cattle diseases occurring during the periparturient period. Additional research is needed in this area to further elucidate the potential protective roles of antioxidants during the periparturient period.

Increased enzymatic activity of $15-\mathrm{LOX} 1$ is associated with several inflammatory-based diseases including atherosclerosis (Bonomini et al., 2008). Metabolism of arachidonic acid by the 15-LOX1 pathway leads to the production of proinflammatory eicosanoids capable of generating ROS and exacerbating oxidative stress. Although 15-LOX1 has not previously been investigated in mammary tissue, this enzyme also may contribute to the pro-oxidant conditions associated with the periparturient period. For example, a recent study demonstrated that 15-LOX1 and its immediate metabolites were responsible for enhanced ICAM-1 expression in cultured bovine endothelial cells subjected to oxidative stress (Sordillo et al., 2008). In the current study, mammary tissue samples from EL had a greater abundance of 15-LOX1 mRNA compared with those obtained at other time points $(P<0.01$; Figure 5$)$. An increase in 15-LOX1 activity during the early postpartum period may contribute to the oxidative stress experienced by the cow by increasing ROS within the mammary tissue. Several selenoproteins can regulate the activity of 15-LOX1. For example, TrxR1 regulates the cellular abundance of fatty acid hydroperoxides generated following oxidation of arachidonic acid via the 15-LOX1 pathway (Cao et al., 2000; Weaver et al., 2001; Yu et al., 2004). The increase in both selenoprotein and 15LOX1 mRNA during EL is suggestive of an association among these factors in mammary tissue as well. The findings from this descriptive study support a possible role of $15-\mathrm{LOX} 1$ in the development of oxidative stress

Table 3. Pearson correlation coefficients

\begin{tabular}{llcccl}
\hline Gene $^{1}$ & & GPX1 & GPX4 & TrxR1 & HO-1 \\
\hline 15-LOX & $\mathrm{r}$ & -0.24 & 0.61 & 0.07 & 0.00001 \\
& $P$ & 0.40 & 0.02 & 0.79 & 1.0 \\
ICAM-1 & $\mathrm{r}$ & 0.81 & 0.36 & 0.70 & 0.85 \\
& $P$ & 0.0004 & 0.20 & 0.01 & 0.0001 \\
VCAM-1 & $\mathrm{r}$ & 0.71 & 0.57 & 0.94 & 0.65 \\
& $P$ & 0.004 & 0.03 & $<0.0001$ & 0.01 \\
\hline
\end{tabular}

${ }^{1}$ GPX1 = glutathione peroxidase; GPX4 = phospholipid hydroperoxide; TrxR1 = thioredoxin reductase; HO-1 $=$ heme-oxygenase; 15-LOX = 15-lipoxygenase 1; ICAM-1 = intercellular adhesion molecule-1; VCAM-1 = vascular cell adhesion molecule-1. 


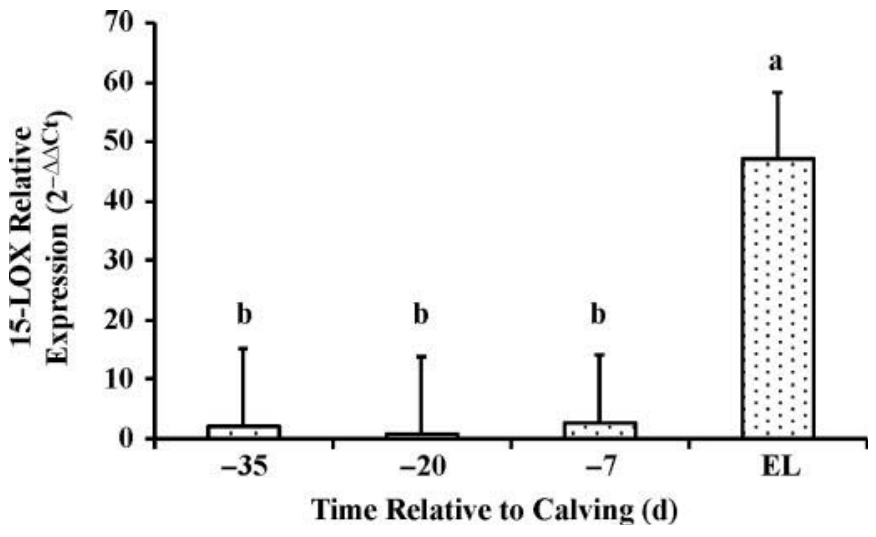

Figure 5. Alterations in mRNA abundance of 15-lipoxygenase 1 (15-LOX1) in the bovine mammary tissue obtained at $-35,-20$, and $-7 \mathrm{~d}$ relative to calving and at early lactation (EL). Data were analyzed by the $2^{-\Delta \Delta \mathrm{Ct}}$ method with $-35 \mathrm{~d}$ as the reference expression point. Data reported as least squares means \pm SEM. Significant differences $(P<0.05)$ between days are represented by different letters.

during the periparturient period and warrants further investigation.

\section{CONCLUSIONS}

Dairy cattle are exposed to oxidative stress during the periparturient period. Oxidative stress may be an underlying cause of increased susceptibility to diseases such as mastitis. Increased gene expression of proinflammatory factors may be a consequence of increased oxidative stress within the mammary gland during the onset of copious milk synthesis and secretion. This study demonstrates that the mRNA expression of several antioxidant enzymes decreases as parturition approaches and then increases after parturition. The expression of 2 key proinflammatory adhesion molecules, however, also decreases as parturition approaches and then increases afterwards. Results from this descriptive study provide no evidence for cause and effect mechanisms, but we suggest that further studies are warranted. It may be possible to target some of these antioxidant defense mechanisms for intervention during oxidative stress in an attempt to control inflammation and decrease susceptibility to acute mastitis in transition dairy cattle.

\section{ACKNOWLEDGMENTS}

This work was supported in part by a grant from the National Research Initiative of the USDA Cooperative State Research, Education, and Extension Service, grant number \# 2007-35204-18463 and by an endowment from the Matilda R. Wilson Fund (Detroit, MI).

\section{REFERENCES}

Balla, J., G. M. Vercellotti, V. Jeney, A. Yachie, Z. Varga, H. S. Jacob, J. W. Eaton, and G. Balla. 2007. Heme, heme oxygenase, and ferritin: How the vascular endothelium survives (and dies) in an iron-rich environment. Antioxid. Redox Signal. 9:2119-2137.

Bernabucci, U., B. Ronchi, N. Lacetera, and A. Nardone. 2005. Influence of body condition score on relationships between metabolic status and oxidative stress in periparturient dairy cows. J. Dairy Sci. 88:2017-2026.

Bionaz, M., and J. J. Loor. 2007. Identification of reference genes for quantitative real-time PCR in the bovine mammary gland during the lactation cycle. Physiol. Genomics 29:312-319.

Bionaz, M., E. Trevisi, L. Calamari, F. Librandi, A. Ferrari, and G. Bertoni. 2007. Plasma paraoxonase, health, inflammatory conditions, and liver function in transition dairy cows. J. Dairy Sci. 90:1740-1750.

Bonomini, F., S. Tengattini, A. Fabiano, R. Bianchi, and R. Rezzani. 2008. Atherosclerosis and oxidative stress. Histol. Histopathol. 23:381-390.

Brigelius-Flohe, R. 2006. Glutathione peroxidases and redox-regulated transcription factors. Biol. Chem. 387:1329-1335.

Bruzelius, K., T. Hoac, R. Sundler, G. Onning, and B. Akesson. 2007. Occurrence of selenoprotein enzyme activities and mRNA in bovine mammary tissue. J. Dairy Sci. 90:918-927.

Cao, Y. Z., C. C. Reddy, and L. M. Sordillo. 2000. Altered eicosanoid biosynthesis in selenium-deficient endothelial cells. Free Radic. Biol. Med. 28:381-389.

Capuco, A. V., R. M. Akers, and J. J. Smith. 1997. Mammary growth in Holstein cows during the dry period: quantification of nucleic acids and histology. J. Dairy Sci. 80:477-487.

Castillo, C., J. Hernandez, A. Bravo, M. Lopez-Alonso, V. Pereira, and J. L. Benedito. 2005. Oxidative status during late pregnancy and early lactation in dairy cows. Vet. J. 169:286-292.

Cuschieri, J., and R. V. Maier. 2007. Oxidative stress, lipid rafts, and macrophage reprogramming. Antioxid. Redox Signal. 9:14851498.

Hill, K. E., G. W. McCollum, M. E. Boeglin, and R. F. Burk. 1997. Thioredoxin reductase activity is decreased by selenium deficiency. Biochem. Biophys. Res. Commun. 234:293-295.

Hodgkinson, A. J., E. A. Carpenter, C. S. Smith, P. C. Molan, and C. G. Prosser. 2007. Adhesion molecule expression in the bovine mammary gland. Vet. Immunol. Immunopathol. 115:205-215.

Holmgren, A., and M. Björnstedt. 1995. Thioredoxin and thioredoxin reductase. Methods Enzymol. 252:199-208.

Ishikawa, Y., K. Nakada, K. Hagiwara, R. Kirisawa, H. Iwai, M. Moriyoshi, and Y. Sawamukai. 2004. Changes in interleukin-6 concentration in peripheral blood of pre- and post-partum dairy cattle and its relationship to postpartum reproductive diseases. J. Vet. Med. Sci. 66:1403-1408.

Kimura, K., J. P. Goff, M. E. Kehrli Jr., and T. A. Reinhardt. 2002. Decreased neutrophil function as a cause of retained placenta in dairy cattle. J. Dairy Sci. 85:544-550.

Livak, K. J., and T. D. Schmittgen. 2001. Analysis of relative gene expression data using real-time quantitative PCR and the 2(-Delta Delta C(T)) method. Methods 25:402-408.

Miller, J. K., E. Brzezinska-Slebodzinska, and F. C. Madsen. 1993. Oxidative stress, antioxidants, and animal function. J. Dairy Sci. 76:2812-2823.

O'Boyle, N., C. M. Corl, J. C. Gandy, and L. M. Sordillo. 2006. Relationship of body condition score and oxidant stress to tumor necrosis factor expression in dairy cattle. Vet. Immunol. Immunopathol. 113:297-304.

Oviedo-Boyso, J., J. J. Valdez-Alarcon, M. Cajero-Juarez, A. OchoaZarzosa, J. E. Lopez-Meza, A. Bravo-Patino, and V. M. BaizabalAguirre. 2007. Innate immune response of bovine mammary gland to pathogenic bacteria responsible for mastitis. J. Infect. 54:399 409.

Papp, L. V., J. Lu, A. Holmgren, and K. K. Khanna. 2007. From selenium to selenoproteins: Synthesis, identity, and their role in human health. Antioxid. Redox Signal. 9:775-806. 
Radi, Z. A., M. E. Kehrli Jr., and M. R. Ackermann. 2001. Cell adhesion molecules, leukocyte trafficking, and strategies to reduce leukocyte infiltration. J. Vet. Intern. Med. 15:516-529.

Sharma, B. K., M. J. Vandehaar, and N. K. Ames. 1994. Expression of insulin-like growth factor-I in cows at different stages of lactation and in late lactation cows treated with somatotropin. J. Dairy Sci. $77: 2232-2241$

Smith, K. L., J. H. Harrison, D. D. Hancock, D. A. Todhunter, and H. R. Conrad. 1984. Effect of vitamin E and selenium supplementation on incidence of clinical mastitis and duration of clinical symptoms. J. Dairy Sci. 67:1293-1300.

Smith, K. L., J. S. Hogan, and W. P. Weiss. 1997. Dietary vitamin $\mathrm{E}$ and selenium affect mastitis and milk quality. J. Anim. Sci. $75: 1659-1665$

Sordillo, L. M., H. SooHoo, K. M. Aherne, C. C. Reddy, and J. S. Hogan. 1998. A method to reduce glutathione peroxidase levels in primary endothlial cell cultures. Methods Cell Sci. 19:243-253.

Sordillo, L. M. 2005. Factors affecting mammary gland immunity and mastitis susceptibility. Livest. Prod. Sci. 98:89-99.

Sordillo, L. M., and S. Aitken. 2009. Impact of oxidative stress on the health and immune function of dairy cattle. Vet. Immunol Immunopathol. doi:10.1016/j.vetimm.2008.10.305

Sordillo, L. M., N. O'Boyle, J. C. Gandy, C. M. Corl, and E. Hamilton. 2007. Shifts in thioredoxin reductase activity and oxidant status in mononuclear cells obtained from transition dairy cattle. J. Dairy Sci. 90:1186-1192.

Sordillo, L. M., G. M. Pighetti, and M. R. Davis. 1995. Enhanced production of bovine tumor necrosis factor-alpha during the periparturient period. Vet. Immunol. Immunopathol. 49:263270 .
Sordillo, L. M., K. L. Streicher, I. K. Mullarky, J. C. Gandy, W. Trigona, and C. M. Corl. 2008. Selenium inhibits 15-hydroperoxyoctadecadienoic acid-induced intracellular adhesion molecule expression in aortic endothelial cells. Free Radic. Biol. Med. 44:34-43.

Trigona, W. L., I. K. Mullarky, Y. Cao, and L. M. Sordillo. 2006 Thioredoxin reductase regulates the induction of haem oxygenase-1 expression in aortic endothelial cells. Biochem. J. 394:207-216.

Valko, M., D. Leibfritz, J. Moncol, M. T. Cronin, M. Mazur, and J. Telser. 2007. Free radicals and antioxidants in normal physiological functions and human disease. Int. J. Biochem. Cell Biol. 39:4484 .

Wagener, F. A.. J. L. da Silva, T. Farley, T. de Witte, A. Kappas, and N. G. Abraham. 1999. Differential effects of heme oxygenase isoforms on heme mediation of endothelial intracellular adhesion molecule 1 expression. J. Pharmacol. Exp. Ther. 291:416-423.

Weaver, J. A., J. F. Maddox, Y. Z. Cao, I. K. Mullarky, and L. M. Sordillo. 2001. Increased 15-HPETE production decreases prostacyclin synthase activity during oxidant stress in aortic endothelial cells. Free Radic. Biol. Med. 30:299-308.

Wu, Q., K. Huang, and H. Xu. 2003. Effects of long-term selenium deficiency on glutathione peroxidase and thioredoxin reductase activities and expressions in rat aorta. J. Inorg. Biochem. 94:301306.

Yu, M. K., P. J. Moos, P. Cassidy, M. Wade, and F. A. Fitzpatrick. 2004. Conditional expression of 15-lipoxygenase-1 inhibits the selenoenzyme thioredoxin reductase: Modulation of selenoprotein by lipoxygenase enzymes. J. Biol. Chem. 279:28028-28035. 